\title{
Arquitectura mutable en la vivienda unifamiliar*
}

\author{
Arq. Matías Borgeaud, Fadu/unl
}

* Reseña de la tesina de graduación de la carrera de Arquitectura. Selección de la Cátedra.

1 Bauman, Z.: Modernidad líquida. Prólogo, acerca de lo leve y líquido, p. 8.

2 Carli, C.: Casas que hacen casas. Resulta imperioso ensayar otros caminos, p. 20.

3 Carli, C.: Casas que hacen casas. Primera Parte, Cuando los muros se hacen móviles, p. 40.

4 Gropius, W.: Alcances

de la Arquitectura Integral, II. El arquitecto contemporáneo, 6 . ¿Arqueología o Arquitectura para lo edificios contemporáneos?, p. 94
Mi filosofía de diseño se encuentra representada en esta tesis, siendo el resultado de un proceso reflexivo que vengo desarrollando desde mis primeros años de formación hasta estos días. Esa secuencia estuvo siempre acompañada por mi pasión por la cinética, tendencia intuitiva que con el paso del tiempo creí advertir que podía ampliar el universo de la arquitectura. Naturalmente esta asociación entre la cinética y la arquitectura parece contravenir la naturaleza esencial de esta disciplina, atada a la estática y la inmovilidad temporal. Pero el proceso social actual, en plena mutación, hoy hace posible esta confluencia para dar una solución a esta realidad.

Zygmunt Bauman apuesta a explicar la etapa actual de la era moderna a través de una metáfora muy ilustrativa relacionada con la fluidez, y comenta: «todas estas características de los fluidos, implican que los líquidos, a diferencia de los sólidos, no conservan fácilmente su forma. Los fluidos no conservan una forma durante mucho tiempo y están constantemente dispuestos (y proclives) a cambiarla; en cierto sentido, los sólidos cancelan el tiempo; para los líquidos, por el contrario, lo que importa es el tiempo». ${ }^{1}$ Estas razones justifican que consideremos que la fluidez o la liquidez son metáforas adecuadas para aprehender la naturaleza de la fase actual de la historia de la modernidad.

Fluidez, cambio, transformación y aceleración, afectan a la familia, célula social y razón existencial de la vivienda unifamiliar, produciéndose importantes modificaciones en el interior de la misma. Surgen nuevas formas familiares, como las monoparentales, ensambladas, hogares de homosexuales, son una expresión de ese cambio. La ideología de esta tesis parte de considerar a la familia como un producto real-dinámico, en oposición a un producto ideal, estático en el tiempo. Reconociendo la dinámica social actual con sus lógicas, corriendo el velo del perjuicio de sesgar a las familias por una visión unívoca, descentrando así una postura androcéntrica para entender los lazos sociales, reflejando la complejidad y la diversidad en la que está inmersa la familia y que por consiguiente, afectan a la vivienda unifamiliar; invitándonos a reflexionar sobre su rigidez.

Más allá de estas transformaciones, sean positivas o negativas, es necesario señalar que estos cambios se perciben y recienten también en la arquitectura. «La primera reacción será la de cuestionar la arquitectura materializada, hasta ahora, por la rígida caja muraría contenedora; ella es la que establece los limites interiores y exteriores, cuestión que si se analiza con cierta profundidad, muestra que su revisión toca lo más profundo de la disciplina». ${ }^{2}$

\section{Problemática}

«La arquitectura de la vivienda unifamiliar de estos tiempos, rígida y estática no se condice con su esencia, congelando ese gen que representa la vida en tan sólo un instante en relación a los cambios antropológicos que transcurren» (Matías E. Borgeaud).

Esta problemática parte de percibir que el estereotipo funcionalista resulta demasiado rígido para la ya aludida movilidad de la sociedad líquida actual y la falta de congruencia entre esta realidad y la inalterable organización de las plantas funcionalistas que ofrece el panorama vigente. "La conclusión primaria no resulta muy complicada: a una estructura compleja no se puede responder con estereotipos simplificados. A una sociedad en cambio, 0 por mejor decir, en plena crisis, no se la puede encarar empleando viejas estrategias proyectuales que corresponden a períodos superados ostensiblemente a contramano de los nuevos indicadores». ${ }^{3}$

Metaforizando, de la misma manera que Bauman lo hace en su libro, puedo demostrar que el funcionalismo racionalista como derivado directo de esa modernidad sólida, estable y rígida, debería ser introducido en el crisol de la misma manera que le sucede a la modernidad que perteneció y dio respuesta. Acompañando este proceso desde nuestra disciplina, dando paso a una arquitectura que sepa leer esta realidad y que someta sus muros y elementos compositivos a una licuefacción, transformándolos en cuerpos elásticos-mutables, para poder dar respuesta a las necesidades de esta modernidad líquida, la que hoy respiramos y vivimos día a día. Así nace la Arquitectura mutable...

\section{Hipótesis}

«La arquitectura debería pasar de ser estática para convertirse en dinámica-mutable como un reflejo de la vida, debe evolucionar, transformándose en la piel que envuelva las necesidades del humano a lo largo de su existencia, que vaya cambiando en base a las circunstancias y requerimientos del hombre y que no sea él quien se 

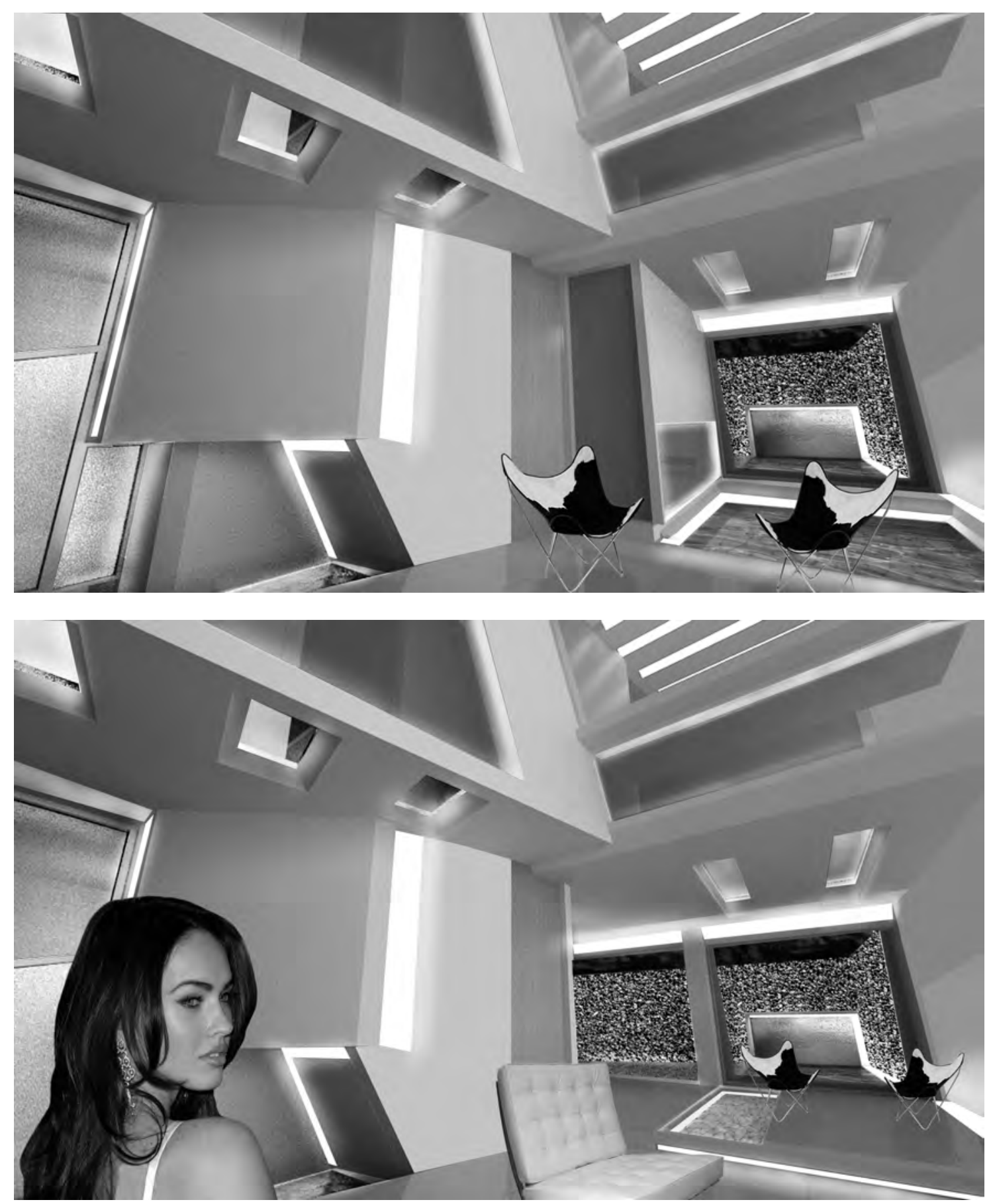

Mutabilidad No 1: Arriba: segregación comedor-estar. Abajo: fusión comedor+estar. 

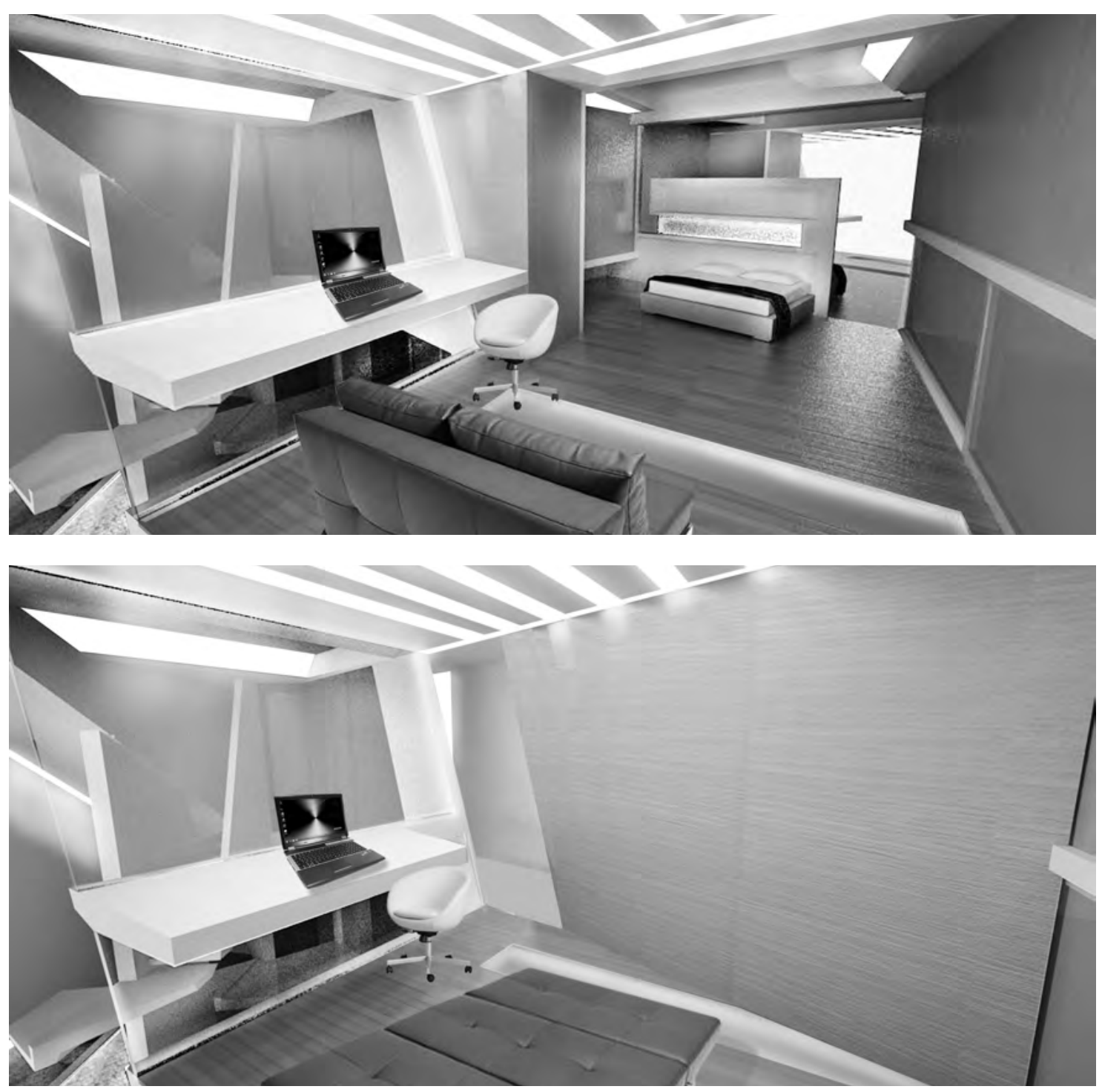

Mutabilidad No 2: Arriba: dormitorio unificado. Abajo: segregación de dormitorio. 
adapte a la misma, manteniendo una relación armónica con el medio ambiente» (Matías E. Borgeaud).

La defino como aquella que su esencia sea como la vida, sinónimo de dinamismo, cambio, mutación en donde la cinética (propia de la vida y su entorno) reemplaza la estática y la rigidez de la arquitectura tradicional. Con una habitabilidad basada en la permanente movilidad social y la libertad de opciones, alterando así su organigrama básico con el objetivo de satisfacer las necesidades sociales y antropológicas, en continua mutación. Esto se lograría con la incorporación de los muros mutables que modificarían la dimensión de los locales produciendo adecuaciones a situaciones imprevistas. De esta forma se generaría un ámbito receptivo para toda inquietud que va apareciendo en el acto de vivir.

Para finalizar, voy a exponer una cita de Walter Gropius que refleja la ideología básica de esta tesis. Quizás parezca contradictorio por tratarse de uno de los maestros de la arquitectura que se cuestiona, pero la intención de la misma refleja el carácter heterodoxo, reflexivo y de ninguna manera dogmático de este ensayo, demostrando con esto que no se busca catalogar lo anterior como lo peor y lo planteado como lo mejor, sino todo lo contrario, tomarlo como base para poder así seguir progresando y dar paso a esta arquitectura en las puertas de esta nueva realidad social líquida, que seguramente en un tiempo no muy lejano mutará y esta historia se repetirá...

"La arquitectura debe marchar hacia adelante; si no, morirá. Su nueva vida debe provenir de los tremendos cambios producidos en los campos social y técnico durante las dos últimas generaciones. El medievalismo y el colonialismo no pueden expresar la vida del hombre del siglo XX. No existe finalidad en la arquitectura sólo continuo cambio». ${ }^{4}$
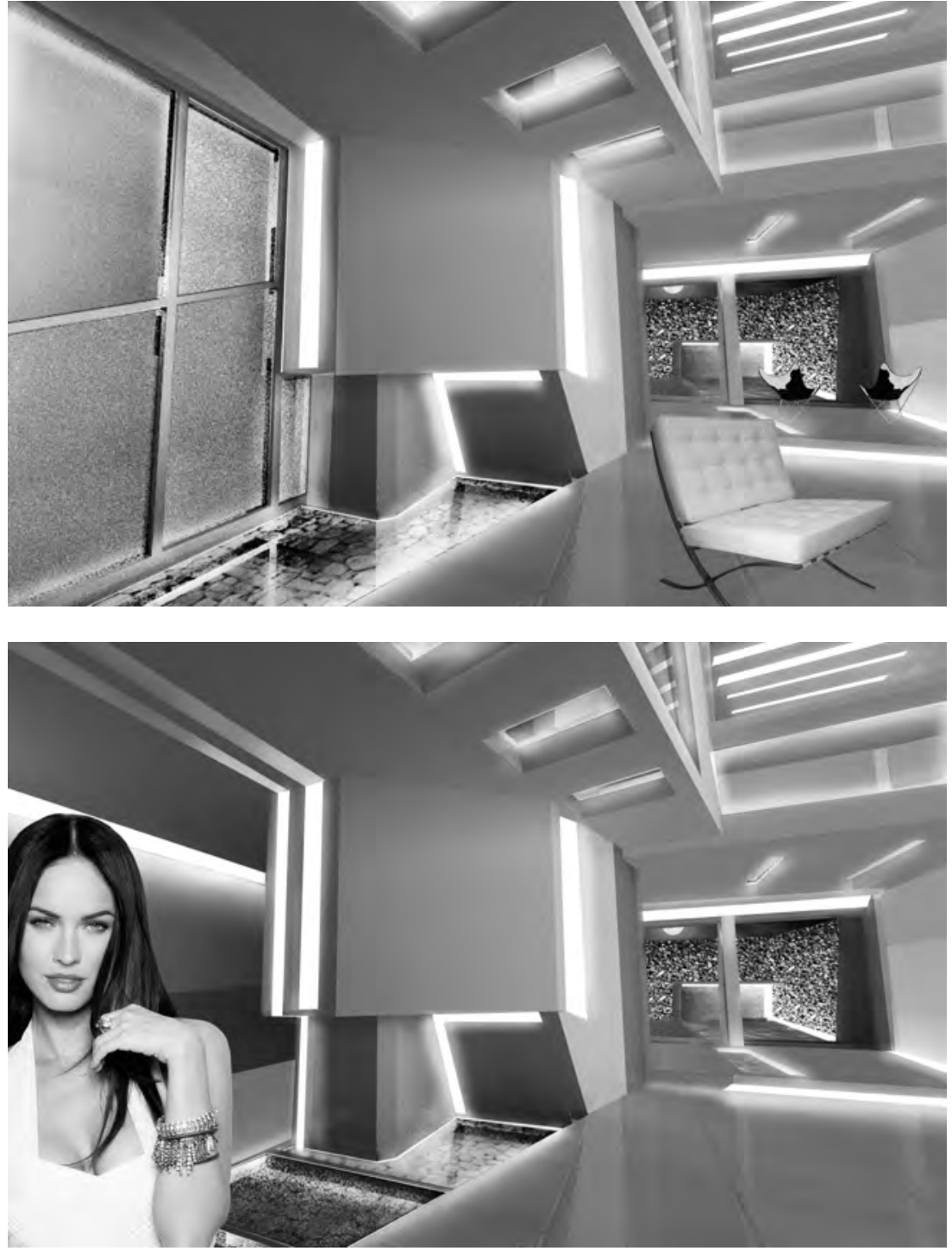

Mutabilidad $\mathrm{N}^{\circ}$ 3: Arriba: planta parcialmente abierta. Abajo: planta abierta. 